Original Article

\title{
Empathy Levels among Medical Students: A Psycho-Social Analysis
}

Sadia Shah ${ }^{1}$, Muhammad Muneeb ${ }^{2}$ \& Aatir H.Rajput ${ }^{2}$

1-Liaquat University of Medical \& Health Sciences, Jamshoro

2-Lumhs Research Forum

Corresponding Author: drsadiashah@outlook.com

\begin{abstract}
Empathy is an important component in a doctor-patient relationship. It is an objective and relatively a stable constitutional trait. The apprehension among educationalists that clinical training may have an adversative effect on medical trainees and student empathy levels, holds truth as indicated by the existing literature. Long work/study hours and sleep deprivation may be the potential reasons believed to contribute to empathy decline. The aim of the study was to determine the changes in the empathy levels among the students, during their medical school years. The opinions and observations of medical students were recorded and interpreted hoping to determine the main reasons behind the changing empathy levels (if present). A psycho- social cross-sectional analysis of medical students' empathy levels was conducted at Liaquat University of Medical and Health Sciences Jamshoro. A 20 item JSPE-S (Jefferson Scale of Physician Empathy-Student Version) self-administered structured questionnaire including 7-point Likert scale was used to evaluate empathy levels among students. Convenient sampling procedure was used. A total of 300 students were approached during their class timings at lecture halls. A prior verbal informed consent was taken and those who agreed were included in the study. The duration of study was from May, 2014 to August, 2014. Data analysis was done via SPSS $16.0 .41 \%(n=123)$ out of 300 participants were male while 59\% $(n=177)$ were females. The mean empathy value of first year students (91.29) was greater than that of final year students (84.53). E.S value i.e. effect size value comes out to be 0.5 , which is moderately significant. Study concluded that the students at LUMHS have the least empathy score in comparison to the standard values. This decline in the empathy levels explains the change of social behavior of the students across their medical school years. It is related to the hectic and difficult time period of their studies, their personal experience with the patients, realization of the difficulties and challenges in seeking medical services.
\end{abstract}

\section{Keywords}

Empathy, Medical students, Liaquat University

\section{Introduction}

Empathy is a psychological term which shouldn't be confused with sympathy. Empathy is an objective and relatively a stable constitutional trait in contrast to sympathy, which is an irregular, non-objective and a non-critical sentiment (Helena, 2014; Lt: Col. R., 2014). Empathy refers to the insightful awareness of an individual to the emotions, feelings and conduct of someone else. It is all about showing warmth, recognition and compassion for the people (Areeb, 2013; Sandara, 2014) .Empathy is considered as an extremely important component in a doctor-patient relationship that involves careful and active listening to the patients, in order to identify, distinguish and understand their problems, show concern about their feelings, and passing on this comprehension. This understanding allows the patient to feel respected and comfortable and can trust the doctor give an appropriate data or history (M. Rahimi, 2010; Deleing, 2013). Empathy is as important and crucial for the medical students as it is for the physicians. The apprehension among educationalists that clinical training may have an adversative effect on medical trainees and student empathy levels, holds truth as indicated by the existing literature. Empathy should be flourished and can be developed among the medical undergraduates during their stay in the medical schools (Kataoka, 2009; Hojat, 2009). The aim of the current study is to measure empathy levels amongst medical students in the first and the final year of their medical curriculum and to check weather this existing phenomenon holds truth in ours locality. Methodology

This cross-sectional quantitative study was conducted at Liaquat University of Medical and Health Sciences, Jamshoro from May, 2014 to August, 2014. A total number of 300 students (including 123 males and 177 females) from First and Final year MBBS were enrolled after taking an informed consent. Students were chosen by simple random sampling and were approached during their class timings in lecture halls, ward classes and practical labs. Students were advised not to identify themselves in any manner except age, gender and medical study year. Every 3rd student in a row was requested to be indulged in the research procedure. A pre-formed structured questionnaire (including Student version of Jefferson Scale of Physician Empathy) was used to get knowledge about students' name, age, gender, educational status, frequency of interaction with people, their classification as emotional or practical, and time given to medical practice daily. The student version (Sversion) of JSPE (Jefferson Scale of Physician Empathy) was used in the study, in its original 
language (English) and format which took approximately 5-7 minutes to get completed. JSPE is a self-administered inventory, containing 20 items. Negative and Positive items were equally phrased. Each item was answered on a seven-point Likert-type scale, ranging from 1 (strongly disagree) to 7 (strongly agree). For negative items, scoring is reversed ( $1=$ strongly agree to $7=$ strongly disagree). The total score was obtained by the sum of all items (scores can range from 20 to 140). Higher values indicate higher level of empathy. The JSPE was originally developed in 2001 to measure medical students' attitudes about physician empathy in a patient-care situation. Items included in the scale were derived from an extensive review literature followed by studies with groups of physicians, medical students and residents. (Hojat et al. 2001; Hojat et al. 2002c). The scale has been validated and found to be reliable in USA, Mexico and Japan (Hojat et al. 2001; Alcorta-Garza et al. 2005; Kataoka et al. 2009). All the responses to the JPSE-S by the medical students were coded and analyzed using SPPS version 16.00. For categorical data, percentages and frequencies was used. For numeric data, mean and standard deviation was used. An independent E.S value i.e. the effect size value was applied to assess the clinical and statistical difference between the empathy levels. (Mean Empathy score of final year - Mean Empathy score of 1st year)/St. Deviation of 1 st year score.

\section{Results}

Of the 330 questionnaires distributed, $91 \%$ i.e. $n=300$ questionnaires were responded completely and included in the study. There were $41 \%$ (123) males and $59 \%$ (177) females. 147 (49\%) respondents were from First year whereas, $153(51 \%)$ respondents from Final year.

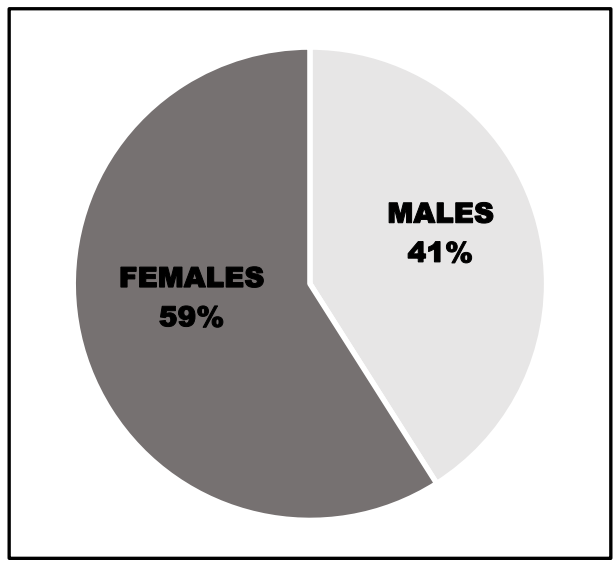

Figure 1 Showing gender distribution of respondents. $59 \%$ of the sample was consisted of female population while males were $41 \%$ of the sample.
A comparative analysis reveals that the mean empathy score for the first year students is 91.29 which is significantly greater than that of the final year students, i.e. 84.53. Though, final year students did not have a higher level of empathy than their first year counterparts, but the difference in the Standard Deviation was not statistically significant. While the E.S value i.e. the effect size value, comes out to be 0.5 , which shows that the clinical and statistical difference between the empathy levels, which is moderately significant. (E.S= Mean Empathy score of final year Mean Empathy score of 1st year/St. deviation of 1st year score).

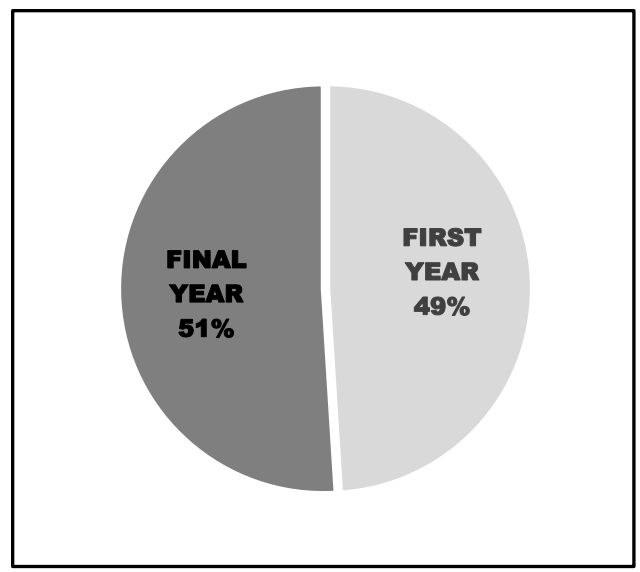

Figure 2; representing educational status of respondents. There were $49 \%$ first year students while $59 \%$ of the sample was from final year

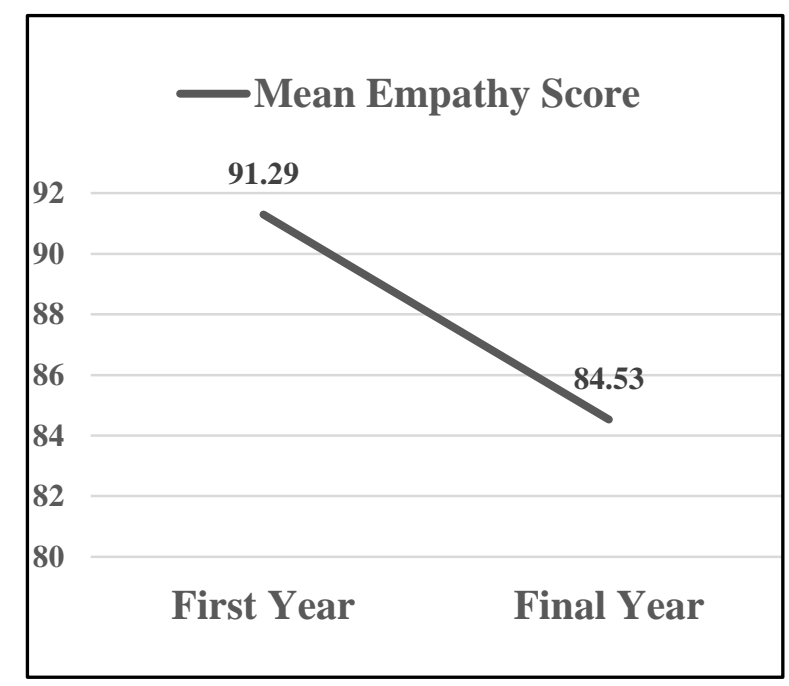

Figure: 3 shows a decline in Mean Empathy Score i.e. 91.29 from first year to 84.53 in final year. 


\begin{tabular}{|l|l|l|}
\hline $\begin{array}{l}\text { DEMOGRAPHIC } \\
\text { VARIABLES }\end{array}$ & No. & MEAN/S.D \\
\hline First Year & 147 & $91.29 / 13.2$ \\
\hline Final Year & 153 & $84.53 / 12.4$ \\
\hline
\end{tabular}

Table: 1. the background demographic of empathy mean scores $(\mathrm{n}=300)$

\section{Discussion}

The results revealed that empathy among the medical students' builds up during the first year of medical education, however it starts to come down after the clinical exposure begins and remains down through the final year of medical school. The variation in JSPE-S score is as incredible as 6.76 between the first year and final year students. The study, albeit crosssectional, is reliable with past studies, recommending that empathy diminishes after the clinical exposure in the medical school. Different stressful aspects of medical training for example long working hours, lack of sleep, depending on technology for diagnosis, shorter hospitalizations of patient and limited bedside interactions may contribute to diminish empathy levels (Rose, 2006; Benbassat, 2004). Another alternate conceivable clarification for the observed decrease in the empathy levels may be cultural assimilation or acculturation phenomenon (Kay, 1990). Medical students encounter an extensive range of emotions and feelings and may struggle to keep up their empathy levels (Kramer, 1989). The results also show that the overall empathy of students at LUMHS is less than the international standard. Bangladesh $($ mean $=110.41)$, China $($ mean $=109.60)$, Japan $($ mean $=104.3)$, Kuwait $($ mean $=104.6)$, Iran $($ mean $=105.1)$ and American medical students $($ mean $=115)$. The possible explanation for this is the overwhelming clinical exposure in our settings which probably train the minds of students in such a way that their empathy levels starts to come down and they start thinking more professionally and practically rather emotionally (Marcus, 1999; Branch, 1993).

\section{Conclusion}

The study concluded that there are differences in empathy among the different classes and that empathy declines with increased clinical training in the medical school. Empathy serves as a key factor in establishing a good doctor-patient relationship. It is thus essential that empathy should be nurtured in medical students rather than swept away with time and clinical exposure, so that the upcoming physicians can serve their patients in the best possible way.

\section{Limitations}

There were several limitations to the study. Due to cross-sectional nature of the study, only the empathy levels among first year and final year students could be examined. It would be of interest to measure how empathy varies with each year throughout the five years of medical school using a prospective longitudinal study design. Secondly, the candidates own self-perception influences his/her choices while filling out the questionnaire and this may vary from the actual behavior that is implemented in their everyday interactions.

\section{Recommendations}

It would be profitable to do a prospective study where the students under study are emulated every year from the first year until graduation, to give a genuine representation of progress in empathy levels. In spite of the fact that the study is constrained to our medical university, we feel that our results could be summed up to restorative universities that have a customary structure like our own.

\section{References}

- Areeb Sohail Bangash, Nasreen Feroze Ali, published online, 16th July, 2013, Maintenance of empathy levels among first and final year students: a cross-sectional study; 2:157

- M. Rahimi, Madiseh Tavakol, Jafar Nasiri, published online at webpaper.com in 2010, Empathy in Iranian medical students:- A preliminary psychometric analysis and differences by gender and year of medical school, vol: 32, No:11 Pg.: 471-478

- Hojat M. Vergara MJ, Maxwell K, Acad Med, 2009, The devil is in third year:- a longitudinal study of erosion of empathy in medical school, vol-84 (n), 1616

- Rose IM, Gimotty PA, Shea JA, Bellini LM, Acad Med. 2006, sleep deprivation, mood disturbances, empathy and burnout among interns; 81:82-85.

- Benbassat J, Baumal R. Acad Med. 2004 What is empathy, and how can it be promoted during clinical clerkships? 79:832-839

- Kay J. JAMA. 1990 Traumatic deidealization and the future of medicine;263:572-3

- Kramer D, Ber R, Moore M, Mes Educ. 1989; Increasing empathy among medical students;23:168-173

- Marcus ER. . Acad Med. 1999 Empathy, humanism, and the professionalization process of medical education; 74:1211-5.

- Branch W, Pels RJ, Lawrence RS, Arky R. N Engl J Med. 1993 Becoming a doctor. Critical- incident reports from third year medical students;329:113032

- Helena B.M.S.Paro, Paulo S.P.Silveria, published in April 04, 2014, Empathy among medical students: Is there a relation with quality of life and burnout? D01:10.1371/journal.pone 0094133 
- Kataoka MU, Koide.N, Ochi.K, Hojat M. Acad Med. 2009, September; Measurements of empathy among Japanese medical students:- psychometrics and score differences by gender and level of medical education; 84 (a) 1192-7

- Lt: Col. R. Shashi Kumar, Richa Chaudhary, April 2014 Cross-sectional assessment of empathy scores among undergraduates from a medical college, Medical Journal of Armed Forces, India, Vol: 70, Issue: 2, pg. 179-185

- Sandara dehning, Eshetu Girma, published online, may,24,2014,Comparative cross-sectional study of empathy among first year and final year medical students in Jimma, University, Ethiopia, Steady State of Heart and Opening of Eyes; 12:34

- Deleing Wen, Xiao Dan Ma, Hong he Li; , published online, sep,23,2013; Empathy in Chinese medical students: Psychometric characteristics and differences by gender and year of medical education, BMC Med edu.2013 13:130 